\title{
Compliance with oral corticosteroids during steroid trials in chronic airways obstruction
}

\author{
M Q F Hatton, M B Allen, S V Vathenen, M P Feely, N J Cooke
}

\begin{abstract}
Background - Corticosteroid trials are an important part of the assessment of patients with chronic airways obstruction, but false negative results will occur if the treatment is not taken. To determine compliance low dose phenobarbitone has been used as a marker.

Methods - Thirty six patients referred to a chest clinic for assessment of their airways obstruction were studied. They were instructed to take eight capsules (each containing $5 \mathrm{mg}$ prednisolone and $0.5 \mathrm{mg}$ phenobarbitone) per day for two weeks. The response was assessed by home peak flow monitoring and clinic spirometric tests. Plasma phenobarbitone levels were measured after the trial to enable calculation of the dose to plasma concentration ratio (level to dose ratio, $L D R$ ) and the result was compared with the reference range for fully compliant individuals.

Results - Five patients defaulted from follow up, 23 had LDR values within the expected range, and eight had low LDR values consistent with poor compliance. The nine patients with steroid responsive disease ( $>20 \%$ improvement in peak flow or spirometric parameters) all had LDR values in the expected range.

Conclusion - Excluding those who defaulted whose compliance must be questionable, eight $(26 \%)$ patients did not fully comply with the steroid trial. Not all patients who fail to respond to a two week home steroid trial have a steroid "unresponsive" disease.

(Thorax 1996;51:323-324)
\end{abstract}

Department of Respiratory Medicine M Q F Hatton $M$ B Allen $S \mathrm{~V}$ Vathenen N J Cooke

University Department of Medicine M P Feely

The General Infirmary at Leeds,

Leeds LS1 3EX, UK

Reprint requests to: Dr M B Allen, Chest Clinic St Luke's Hospital, Bradford BD5 0NA, UK.

Received 18 January 1995 Returned to authors 23 March 1995 Revised version received 1 November 1995 Accepted for publication 5 December 1995
Keywords: chronic airways obstruction, corticosteroid reversibility trials, compliance, phenobarbitone.

A corticosteroid trial is an integral part of the assessment of chronic airways obstruction. Such trials are usually performed with short courses of oral prednisolone and the assessment is based upon changes in twice daily peak flow recordings and/or spirometric parameters at the start and end of the trial. A $20 \%$ improvement over baseline peak flow or forced expiratory volume in one second $\left(F E V_{1}\right)$ is usually accepted as a positive response. ${ }^{1}$

For the trial to be effective compliance is essential; if patients take some or none of the steroid tablets a false negative trial may result. Measurements of compliance that rely on interview or tablet count underestimate non- compliance. Therapeutic drug monitoring is one of the best methods of monitoring compliance but is available for only a few drugs and is limited by individual pharmacokinetic variations, with serum concentrations sometimes reflecting recent drug ingestion. ${ }^{2}$

An alternative method of assessing compliance is by using low dose phenobarbitone which has little interindividual and intraindividual pharmacokinetic variation. ${ }^{3}$ The long half life leads to predictable steady state plasma concentrations after two weeks of regular therapy which cannot be achieved by ingestion of a few tablets before a clinic visit. ${ }^{4}$ The low dose of phenobarbitone used has no discerning sedative effects and does not appreciably induce hepatic enzymes. ${ }^{5}$

By using low doses of phenobarbitone as a marker we have examined compliance during trials of oral corticosteroids for the assessment of chronic airways obstruction.

\section{Methods}

With ethical committee approval, patients with chronic airways obstruction referred for further investigation of breathlessness were recruited, provided they had not previously undergone a steroid trial. Patients attended the clinic between 09.00 and 11.00 hours; spirometric values were measured with a dry wedge spirometer (Vitalograph, UK) and patients were instructed on how to perform twice daily peak flow measurements on charts which contained explicit written instructions. The need for steroids to assess reversibility, importance in planning future treatment, and their short term use and few side effects under these conditions were explained in detail to the patient. They were not told that their compliance was being assessed.

The study medication was $5 \mathrm{mg}$ prednisolone and $0.5 \mathrm{mg}$ phenobarbitone combined in a capsule and patients were asked to take eight capsules each morning for two weeks ( $40 \mathrm{mg}$ prednisolone, $4 \mathrm{mg}$ phenobarbitone daily). After 14 days the patients returned to the clinic with their peak flow charts and $10 \mathrm{ml}$ of venous blood was taken and spirometric values were again measured. The serum was separated and frozen for subsequent batch analysis of plasma phenobarbitone levels by high performance liquid chromatography. A $20 \%$ or greater increase in either peak flow measurements over the first day or $\mathrm{FEV}_{1}$ was taken as a positive result.

Based on the patient's clinical weight, the ratio of the plasma concentration to phenobarbitone dose was calculated to give the level to dose ratio (LDR) defined as: plasma 


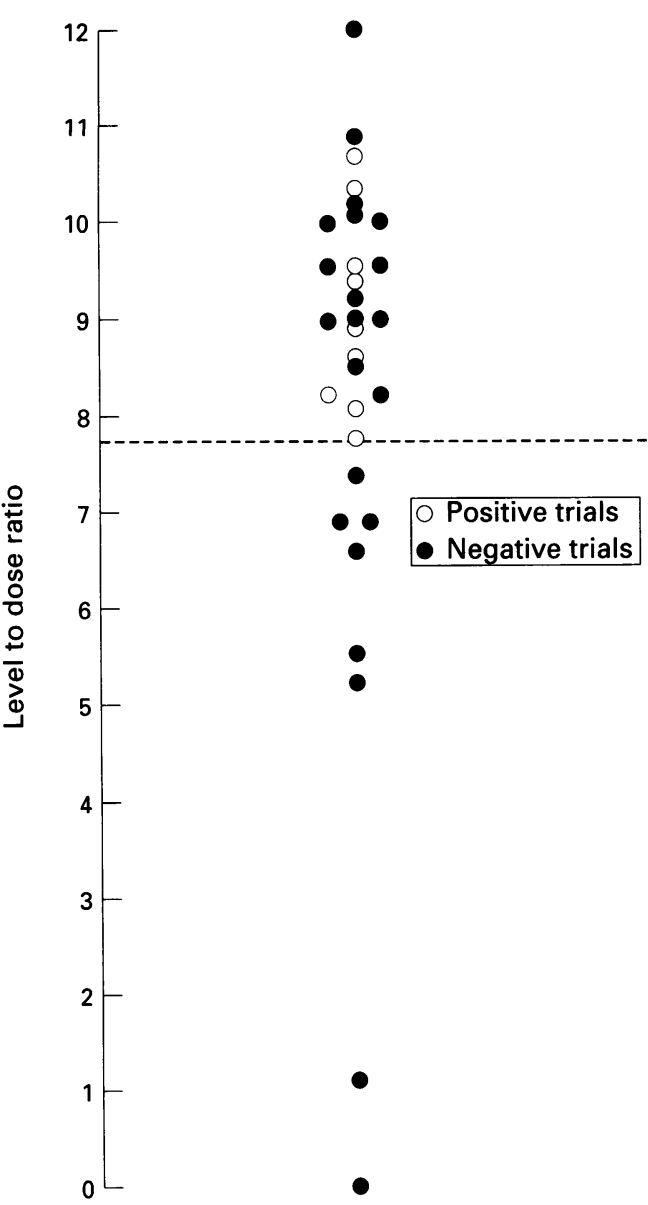

Phenobarbitone level to dose ratio (LDR) for the 31 patients attending after their short steroid trial. Positive results $(O)$ are those where the patient had a $>20 \%$ increase in peak flow and/or spirometric parameters.

phenobarbitone concentration (mg/l)/phenobarbitone dose $(\mathrm{mg} / \mathrm{kg})$. The LDR for the study patients was calculated and compared with the reference range of $7 \cdot 8-14$ obtained from studies in compliant healthy individuals. ${ }^{6}$

\section{Results}

Thirty six patients (20 men) of median age 64 years (range 37-78) were recruited. Five patients (four men) defaulted on follow up at day 14 and, as phenobarbitone levels, peak flow measurements, and spirometric values were not obtained, they were excluded from the analysis. Of the remaining 31 patients nine used bronchodilators alone, two inhaled steroids, and nine patients used both. The mean (SD) baseline spirometric values were: $\mathrm{FEV}_{1} 1 \cdot 1(0.59) \mathrm{l} / \mathrm{s}$, FVC $2 \cdot 0(0 \cdot 86) 1$, and the mean (SD) $\mathrm{FEV}_{1}$ / FVC ratio was $0.55(0.1)$.

Nine patients $(29 \%)$ had steroid responsive disease (defined as a $20 \%$ or greater increase in either peak flow or $\mathrm{FEV}_{1}$ ), with three patients responding on both measurements. Four patients increased their peak flow measurements with a median improvement of 90 $1 / \mathrm{min}(36 \%)$ over the baseline peak flow measurements. Eight patients increased their $\mathrm{FEV}_{1}$ with a median improvement of $0.231 / \mathrm{s}(31 \%)$ from the baseline value.
The calculated LDR for the phenobarbitone showed very low values in two patients (one man) suggesting they had taken little of the prescribed medication (figure). A further six patients (four men) had values well below the expected range, consistent with partial compliance. None of the patients with low LDR values had a positive steroid response. In contrast, the nine patients who were steroid responsive had LDR values in the fully compliant range $\left(\chi^{2} 4 \cdot 4 ; \mathrm{p}<0 \cdot 05\right)$.

\section{Discussion}

We have attempted to assess compliance with oral prednisolone in patients with airways obstruction by using phenobarbitone as a marker. Despite stressing the short term nature of the steroid administration, its benefits in future treatment, and the few side effects, we found that eight of 31 patients failed to comply as determined by their LDR value. Furthermore, five patients failed to return to the clinic so their compliance was also open to question.

The reference LDR range of 7.8-14 is based upon data from fully compliant normal volunteers between the ages of 20 and 50 years. ${ }^{6}$ It is possible that the reference range is a little higher for those over 50 years $^{4}$ which could underestimate the number of partial compliers.

The information which should be given to patients during "informed consent" is a matter for consideration. ${ }^{7}$ The aim of this study was to obtain information on compliance during steroid trials in clinical practice so compliance was not discussed when consent for the study was obtained as it would probably have influenced the patients' tablet ingestion. Ethical committee approval was obtained for this approach as the study met the other criteria which allowed this information to be withheld from the patient. ${ }^{8}$

Poor compliance with medication is becoming increasingly appreciated and may be a greater problem with drugs perceived to be harmful. ${ }^{23}$ Our study suggests that in patients with airways obstruction a negative result does not necessarily imply "unresponsiveness".

We wish to thank Mrs E Mellor and the pharmacy department for preparing the prednisolone plus phenobarbitone capsules and staff at Leeds Chest Clinic for their help in organising the and stafty.

1 Weir DC, Gove RI, Robertson AS, Burge PS. Corticosteroid trials in non-asthmatic chronic airflow obstruction: a comparison of oral prednisolone and inhaled beclomethasone dipropionate. Thorax 1990;45:112-7.

2 Wright EC. Non-compliance - or how many aunts has Matilda. Lancet 1993;342:909-13.

3 Pullar T, Feely M. Problems of compliance with drug treatment: new solutions. Pharm f 1990;245:213-5.

4 Feely M, Cooke J, Price D, Singleton S, Mehta A, Bradford $\mathrm{L}$, et al. Low-dose phenobarbitone as an indicator of com$\mathrm{L}$, et al. Low-dose phenobarbitone as an indicator of com-
pliance with drug therapy. Br $\mathcal{f}$ Clin Pharmacol 1987;24: pliance

5 Price D, Mehta A, Park BK, Hay A, Feely M. The effect Price D, Mehta A, Park BK, Hay A, Feely M. The effect
of low dose phenobarbitone on three indices of hepatic of low dose phenobarbitone on three indices of hepatic
microsomal enzyme induction. Br $\mathcal{F}$ Clin Pharmacol 1986; 22:744-7

6 Bignell CJ, Mulcahy FM, Peaker S, Pullar T, Feely MP. Measuring treatment compliance of men with non-gonococcal urethritis receiving oxytetracycline combined with low dose phenobarbitone. Genitourin Med 1988;64:312-5. 7 Thornton H. Understanding "informed consent". Lancet 1995;346:1047-8.

8 Levine RJ. Monitoring for adherence: ethical considerations. Am $\mathcal{f}$ Respir Crit Care Med 1994;149:287-8. 